\title{
Construction of Stance through the Use of Retrospective Labels by American and Turkish Academic Writers
}

\author{
Huseyin Kafes ${ }^{1}$ \\ ${ }^{1}$ Akdeniz University, Faculty of Education, Antalya, Turkey \\ Correspondence: Huseyin Kafes, Akdeniz University, Faculty of Education, Antalya, Turkey. E-mail: \\ hkafes@akdeniz.edu.tr
}

Received: September 16, 2017

Accepted: October 10, 2017 Online Published: October 12, 2017

doi: 10.5539/elt.v10n11p87

URL: http://doi.org/10.5539/elt.v10n11p87

\begin{abstract}
In parallel with the recognition of the importance of writer presence in academic texts, there has been an increasing interest in writer stance. Yet, very little of this research has been devoted to the construction of stance through retrospective labels. Driven by this need, this study aims to investigate the construction of stance through retrospective labels by American and novice Turkish writers in their texts. Using a corpus-based methodology comprising of quantitative and qualitative procedures, this study analyzes the frequency counts of stance through retrospective labels and the functions associated with them. The results of this corpus-based research have revealed similarities as well as some marked differences between the two corpora. It seems that in addition to proficiency in English, educational background of novice Turkish academic writers have an impact on their construction of stance through retrospective labels. I suggest that the strategic employment of retrospective labels to create stance is a valuable rhetorical strategy for academic writers to construct convincing arguments.
\end{abstract}

Keywords: academic writing, research article, stance, retrospective labels

\section{Introduction}

In the last two decades or so, we have witnessed a notable upsurge of interest in stance, especially writer stance, as a result of the ever-increasing recognition of the importance of writer-reader relationship and writer presence and involvement in academic texts. Stance has been defined as "the lexical and grammatical expression of attitudes, feelings, judgments, or commitment concerning the propositional content of a message" (Biber \& Finnegan, 1989, p. 92). Underlying the importance of interpersonal dimension of academic texts and viewing stance as "the writer's textual "voice" or community recognized personality, an attitudinal, writer-oriented function" (Hyland, 2011, p. 197), he sees stance as the various "ways writers present themselves and convey their judgments, opinions, and commitments, intruding to stamp their personal authority onto their arguments or step back and disguise their involvement (Hyland, 2005, p. 176). It is this interpersonal feature of academic texts that helps create persuasive texts. That is, the persuasiveness of academic texts depends upon "writer's development of an appropriate relationship with his or her readers as well as the demonstration of absolute truth, empirical evidence, or flawless logic" (Hyland, 2001, p. 549).

Although a considerable amount of literature has focused on nouns which allow writers to incorporate interpersonal meanings in the texts (Bazerman, 1988; Barton, 1993; Biber \& Finegan, 1988, 1989; Conrad \& Biber, 2000; Hoey, 2000; Hunston, 1989, 1993, 1994; Hyland, 1999, 2000; Swlaes, 1990; Thetela, 1997; Thompson \& Ye, 1991; Winter, 1982), the use of nouns, especially sentence initial nouns preceded by deictics, to construct stance in academic writing has so far attracted little attention. The research on the construction of stance has focused mainly on modal verbs, epistemic verbs, adverbs, adjective, and nouns (A ğçam, 2015ab; Akbas, 2014; Biber \& Finegan, 1988; Cakir, 2016; Chafe, 1986; Conrad \& Biber, 2000; Fraser, 1980; Holmes, 1984; Hoye, 1997; Hunston, 1994; Hunston \& Thompson, 2000; Hyland, 1996, 1998, 1999, 2002, 2004, 2005; Hyland \& Tse, 2005; Kafes, 2009; Martin \& White, 2005; Silver, 2003; Stotesbury, 2003; Stubbs, 1986; Thompson \& Ye, 1991; Uysal, 2014; Yağız \& Demir,; 2014, 2015). Much of the extant research on nouns has so far dealt with lexical cohesion. It is this cohesion-creating feature of these nouns that has drawn a lot of attention. The nouns which have been employed to construct lexical cohesion have been labeled differently: anaphoric nouns, advance/retrospective labels (Francis, 1986, 1994); signaling nouns (Flowerdew, 2003, 2006); general 
nouns (Halliday \& Hasan, 1976); enumerative/catch-all nouns (Hinkel, 2001; Tadros, 1994); shell nouns (Schmid, 2000; Aktas \& Cortes, 2008; and carrier nouns (Ivanic, 1991).

Francis, who has researched these nouns extensively, labels these nouns as "advance/retrospective labels", which are "inherently unspecific nominal elements' that require lexical realization in the co-text (Francis, 1994, p. 83). She names nominal groups that refer to forthcoming propositions 'advance labels' and those that refer to earlier propositions 'retrospective labels' (Francis 1994: 83). "A retrospective label serves to encapsulate or package a stretch of discourse" (Ibid, 85). That is, a retrospective label 'encapsulates' the whole of a previous proposition (Sinclair, 1981, 1992, 1993), so that its meaning is present in the following sentence. A retrospective label has to meet two criteria: it should not be repetition or a 'synonym' of any preceding element; it must be equivalent to the clause or clauses it replaces, and it should name them for the first time. Retrospective labels serve an important organizational function: while they "may extend its topic-linking capacity over a very small stretch of discourse, they also introduce changes of topic, or a shift within a topic, while preserving continuity" (Francis, 1994, p. 87). By reconsidering a previously expressed issue, writers can build on it and develop their arguments. As remarked earlier, although a plethora of studies have been conducted on the constructions of stance through the use of modal verbs, epistemic verbs, adverbs, nouns, and adjectives, no study has been done comparing published American academic writers' (AWs) and novice Turkish academic writers' (NWs) construction of stance through the use of sentence initial nouns preceded by deictics. Motivated by this apparent need, in this paper I will focus specifically on the use of retrospective labels in the construction of stance by AWs and NWs, as seen in (1) below. This plea is lexicalized in the previous sentence and clearly expresses the position and attitude of the writer towards Raymond's argument as well as serving as a cohesive device.

(1) ... Similarly, Raymond made a vigorous argument in favor of relying on science to lead environmental policy, explaining the need to "educate the regulators into finding out that science should be the base of environmental decisions" (statement 188). This plea was triggered by the paper's explanation of requirements for water temperature of brown trout streams... (AWs 42) (Italics added)

The label This plea encapsulates the whole of the previous sentence, illustrating the writer's perception of Raymond' utterance. By labeling Raymond's statement as plea, the writer clearly expresses her/his stance towards the issue in hand. As we can see, the same effect would not have been created by linking the two sentences with the deictic This alone. It is also interesting to note that a layperson might probably view the same issue differently and thus prefer a different label to name it. As we can see, the use of retrospective labels also shows that the writer is taking a stance as a member of a given disciplinary community. In addition to indicating the writer's stance towards the issue in hand, such use of retrospective labels, which are inherently interactive, "affects the reader's perception of the proposition(s) put forward and so enables the reader to perceive the organization and meaning that the writer intends" (Charles, 2003, p. 381).

\section{Methodology}

This corpus-based qualitative and quantitative study investigates the construction of stance in research articles by AWs and MA thesis by NWs through the use of sentence initial nouns preceded by deictics such as this and such. The corpora consist of 20 research articles (RAs) by AWs, published in well-known journals and 20 MA thesis by NWs from the field of applied linguistics. After selecting 100 experimental research articles from well-known journals, the articles by multi-authored ones were excluded. Among the remaining 60 RAs, 20 of them were chosen using random sampling; six articles from TESOL QUARTERLY, six articles from Written Communication, three articles from Journal of English for Academic Purposes, two articles from Journal of Second Language Writing, two articles from English for Specific Purposes, and one article from Journal of Pragmatics. In deciding on American writers' identity, their names and surnames, location of their institutions, and the information given in their CVs were taken into consideration. Similarly, after downloading $100 \mathrm{MA}$ thesis from the official website of Turkish Council of Higher Education Thesis Center, only one MA thesis from the same university was chosen. MA thesis which native speaking English teachers served as thesis advisors were excluded. Finally, 20 MA thesis were randomly chosen from among the remaining 60 MA thesis to form the NWs corpus.

All instances of sentence initial This +noun and Such+noun were identified by using concordance software from WordSmith Tools (Scott, 1996), and they were retrieved from both corpora and examined in their context to determine if they were functioning as retrospective labels or not. During this process, it was made sure that the retrospective labels meet two criteria: They were not repetition or a 'synonym' of any preceding element; that is, they were equivalent to the clause or clauses they replaced, and they named them for the first time. For example, 
since This vision in the following excerpt is simply a repetition of a noun from the preceding sentence, it was not considered as a retrospective label. Such labels were not considered as a retrospective labels.

...The teacher-supervisor relationship is at the core of reflective practice, but once a good relationship is established, it must be supported by an effort to create a shared vision of supervision. This vision necessitates consensus on the conceptualization of teacher education, the separation of evaluation from the supervisory process, and the recognition of trust as a construct that permeates the entire process... (AWs)

Contrary to the excerpt above, the following includes the phrase This paradox, which clearly matches the two requirements of a retrospective label; it is not the repetition or synonym of a preceding element and it is equivalent to the clause it replaces. As seen, it also names the preceding element for the first time. By reconsidering the issue previously expressed, it enables the writer to build on it. In addition to illustrating the writer's stance towards the issue, it also aims to influence the reader's perception of it. Therefore, such phrases were considered as retrospective labels.

...Comparing with the results of the Item 22 presented in Table 43, the students in Mechanical Engineering Department is consistent with their choices because they acknowledge the necessity for after-class efforts no matter how good is the English education provided by the university. However, the freshman students of the Civil Engineering Department and City and Regional Planning Department agree with neither studying out of school nor having the necessary English at school. This paradox may be explained by the negative attitude of these students towards English... (NWs).

\section{Results}

To address the construction of stance by AWs and NWs through the use of retrospective labels, both quantitative and textual analyses were conducted. We first present the results of the quantitative analyses, and then summarize prominent patterns identified by the qualitative analyses.

\subsection{Frequency of This +noun and Such+noun Structures across the Corpora}

Table 1 below presents descriptive statistics for the use of This+noun and Such+noun structures by both groups. Two points attract our attention here. The first one is that NWs employed a lot more of these structures than AWs, which is not surprising given the voluminous size of MA thesis. The other interesting issue regarding the use of these two structures is NWs' overuse of This+noun structure and underuse of Such+noun structure. Although both groups used This+noun structure a lot more than Such+noun structure, AWs writers seem to have employed these two structures a little more evenly than NWs.

Table 1. The distribution of This+noun and Such+noun structures across the corpora

\begin{tabular}{llllll}
\hline & This + noun & $\%$ & Such + noun & $\%$ & Total \\
\hline AWs & 193 & 80.4 & 47 & 19.6 & 240 \\
NWs & 542 & 96.2 & 21 & 3.8 & 563 \\
\hline
\end{tabular}

Both groups' underuse of Such+noun structure in sentence initial position is striking, deserving close scrutiny.

\subsection{Frequency of Retrospective Labels across the Corpora}

The quantitative results show the importance of retrospective labels in creating stance in academic writing. AWs employed a total of 240 of these structures; 193 occurrences of This +noun structure and 47 occurrences of Such +noun structure. NWs, on the other hand, used a total of 563 of these structures; 524 occurrences of this +noun structure and 37 occurrences of Such+noun structure. What looks interesting is the share of the percentages of retrospective labels in these total numbers. 
Table 2. The frequency distribution of retrospective labels

\begin{tabular}{lllll}
\hline & AWs & \multicolumn{3}{l}{ NWs } \\
\hline This+noun, retrospective label & 169 & $87.6 \%$ & 188 & $35.9 \%$ \\
This+noun, repetition/synonym & 24 & $12.4 \%$ & 336 & $64.1 \%$ \\
Total & 193 & & 524 & \\
& & & & \\
Such+noun, retrospective label & 35 & $74.5 \%$ & 21 & $56.8 \%$ \\
Such+noun, repetition/synonym & 12 & $25.5 \%$ & 16 & $43.2 \%$ \\
\hline Total & 47 & & 37 & \\
\hline
\end{tabular}

Of the 193 tokens of This +noun structure, AWs used $87.6 \%$ of them as retrospective labels to construct stance, while they used the rest, $12.4 \%$, to create lexical cohesion in the form of synonym or repetition of a previously used lexical item. When it comes to the use of Such+noun structure, we observe similar percentages. Of the 35 tokens of Such+noun structure, AWs employed $74.5 \%$ of them as retrospective labels to construct stance, while using $25.5 \%$ to create lexical cohesion. As can be seen, AWs employed more than $74 \%$ of This + noun and Such+noun structures to construct stance, which is a clear indication of the importance they have attached to stance in academic writing. NWs, on the other hand, displayed almost an opposite preference. They used only $35.9 \%$ of the total occurrences of 524 This + noun structure as retrospective labels to construct stance, while employing the majority, $64.1 \%$, to create lexical cohesion. Similarly, they used $56.8 \%$ of the total occurrences of $35 \%$ of Such+noun structure to create stance, while using the rest to create lexical cohesion. In other words, contrary to AWs, NWs employed most of This+noun and Such+noun structures to achieve lexical cohesion in their texts rather than to construct stance. This finding illustrates that they seemed to attach less importance to constructing stance than AWs, using these two structures. By employing fewer retrospective labels, they also provided their readers with fewer signposts to guide them through the discourse and attached less importance to building relationship with their readers.

\subsection{The Construction of Stance through the Use of Retrospective Labels across the Corpora}

As remarked earlier, "a retrospective label serves to encapsulate or package a stretch of discourse...It is presented as equivalent to the clause or clauses it replace. (Bald and Italics original) (Francis, 1994, p. 85). As seen, a retrospective label guides and/or directs the reader how to interpret the previous stretch of discourse. While illustrating the writers' purpose(s), view(s), and position, writer's stance, it also tells the reader how to interpret the text. The employment of such a dual-purposive rhetorical device requires the writer to take two careful discourse organization-related decisions: deciding on "which information to encapsulate" and how to label this packaged information. By deciding on the information to be labeled, writers organize texts and incorporate their meaning therein by choosing the label itself (Charles, 2003, p. 318), as exemplified in the excerpt below.

...A major theme in the instructional narratives was the relationship between the government and the people. The students occasionally voiced their apprehension of the imbalance of power between the two entities. Specifically, many viewed themselves as powerless and unprotected when the need arose to deal with governmental institutions. This sentiment was not surprising, considering the students' personal histories... (AWs).

The label This sentiment, above, packages or encapsulates the whole of the previous two utterances, which clearly exemplifies the writer's perception of and position on the event described. In the above stretch of discourse, we can see two important decisions made by the writer. First of all, the writer chooses to package the two previous utterances; the writer could have chosen other utterances as well. Secondly, by labeling and describing the two chosen utterances as sentiment, the writer underlies his stance towards the event described. This rhetorical practice allows the writer to make the preceding information available for further argument by labeling as sentiment. While functioning as a discourse organizer, the label also allows the writer to express his stance towards the proposition it encapsulates or packages. In addition to these important rhetorical functions, the retrospective label This sentiment also aims to influence the readers' perception of the event described. Contrary to the excerpt above, the following one, which does not bear the two features of a retrospective label, 
aims to create lexical cohesion rather than to construct stance. As such, it fails to express the writer's stance; it does not aim to influence the reader's perception of the event described either.

...The results of the study shows that adopting an intercultural understanding is necessary if the aim is to help the learners internalize the inextricable relation between language and culture. This relation may be regarded as an abstract phenomenon... (NWs)

\subsection{The 10 Most Frequent Nouns Used in Retrospective Labels across the Corpora}

The distribution of the 10 most frequent head nouns draws our attention to a few issues. For one thing, as can be seen, both corpora share some head nouns such as result, finding, and approach, though their frequency of usage varies. It seems that the two groups had a tendency to employ some different words as well as employing the same head nouns in the 10 most frequent words. In other words, NWs seemed to have a tendency to employ more metalinguistic nouns such as way, finding, and idea in the ten most frequent head nouns. Contrary to NWs, AWs preferred mostly non-metalinguistic nouns in the ten most frequent head nouns. This preference might be related to the fact that NWs had no space limitation as did AWs in their RAs. The final point that draws our attention is NWs' relative overuse of the head noun result, which is probably caused by language proficiency difference.

Table 3. The 10 most frequent head nouns used in retrospective labels

\begin{tabular}{lllll}
\hline & AWs & & NWs & \\
\hline & Head noun & \# times used & Head noun & \# times used \\
\hline 1 & result & 18 & result & 32 \\
2 & study & 17 & situation & 12 \\
3 & finding & 13 & way & 10 \\
4 & difference & 13 & study & 9 \\
5 & feature & 9 & finding & 8 \\
6 & approach & 7 & process & 8 \\
7 & method & 5 & fact & 7 \\
8 & use & 5 & approach & 6 \\
9 & analysis & 5 & idea & 5 \\
10 & question & 5 & change & 4 \\
\hline
\end{tabular}

\section{Conclusion}

In this corpus-based study, I have investigated the construction of stance through the use of retrospective labels by American writers (AWs) and Novice Turkish writers (NWs). Overall, the results of the study have demonstrated the importance of stance through the use of retrospective labels in academic writing, since both groups of academic writers expressed their stance to varying degrees towards issues in hand and guided the reader how the information is to be understood and interpreted.

The results have drawn attention to a couple of similarities as well as some marked differences between these two groups. For one thing, both groups employed This+noun and Such+noun structures to some extent. Also, both groups used This+noun structure a lot more than Such+noun structure. They also shared some head nouns. Another similarity between these two groups is that they both showed a tendency towards using research-related head nouns, which supports previous research (Moreno, 2004). The distribution of these head nouns, however, differs. This type of labelling seems to be a rhetorical strategy for writers to distance themselves from their interpretation of the data and to give the impression that the text speaks for itself; reducing the role of the writer to merely an instrument spelling out the interpretation process.

The findings have also revealed some subtle differences and qualitative discrepancies in the use of retrospective labels to create stance. To start with, AWs employed $87.6 \%$ of This + noun and $74.5 \%$ Such + noun structure to construct stance. Contrary to AWs, NWs used only $35.9 \%$ of This + noun structure and $56.8 \%$ Such + noun structure for the same purpose. That is, while AWs employed the great majority of these two structures to create stance, NWs used less than half of This +noun structure and more than $40 \%$ of Such + noun structure for the same 
goal. In other words, NWs used almost half of these structures to achieve lexical cohesion. This finding shows that they attached less importance to constructing stance than AWs, using these two structures. By employing fewer retrospective labels, they also provided their readers with fewer signposts to guide them through the discourse and attached less importance to building relationship with their readers. The greater employment of stance through retrospective labels by NWs seems to be congruent with the widely acknowledged belief that English favors a writer-responsible style, which is a novel concept for Turkish writers on the whole. This finding supports previous studies (see Mur Duenas, 2003-2004), who demonstrated that American writers employed a lot more retrospective label to construct stance in their academic writing. It may also be due to preferred rhetorical strategies and educational background of the writers. This discrepancy could also be attributed to language proficiency of NWs.

The findings of this qualitative and quantitative study are descriptive rather than definitive. Therefore, it is of course not very reasonable to make broad generalizations. Notwithstanding these findings, some important issues should be addressed in future studies for a more in-depth understating of the use of retrospective labels to construct stance by Turkish academic writers. Future studies may focus on the reasons behind novice Turkish writers' construction of stance, especially through retrospective labels. Experienced Turkish writers' employment of retrospective labels to construct stance in their English and Turkish RAs will also help us see the big picture better.

Despite its limitations, the findings of this study offer some pedagogical implications for novice writers and policy makers. Given the crucial discourse role that stance through the use of retrospective labelling fulfill, it looks imperative that an appropriate pedagogy involve the study of these labels in context. It is obvious that raising undergraduates, graduates, and novice writers' consciousness on the construction of stance through the use of retrospective labels will help them strategically employ these labels to create stance. Given the fact that no academic writing course is offered at undergraduate and graduate level, it seems it is time to give some serious consideration to its implementation at graduate level, at least.

\section{Acknowledgement}

This is part of a larger project on academic writing funded by The Scientific and Technological Research Council of Turkey (TUBITAK).

\section{References}

Ağçam, R. (2015a). A corpus-based study on attitudinal stance in native and non- native academic writing. International Journal of Humanities Social Sciences and Education, 2(8), 123-129.

Ağçam, R. (2015b). Author stance in academic writing: A corpus-based study on epistemic verbs. Journal of Teaching English for Specific and Academic Purposes 3(1), 9-20.

Akbaş, E. (2014). Are they discussing in the same way? Interactional metadiscourse in Turkish writers' texts. In A. Łyda, \& K. Warchał (Eds.), Occupying niches: Interculturality, cross-culturality and aculturality in academic research (pp. 119-133). London/Berlin: Springer.

Aktas, R., N., \& Cortes, V. (2008). Shell nouns as cohesive devices in published and ESL student writing. Journal of English for Academic Purposes 7, 3-14. https://doi.org/10.1016/j.jeap.2008.02.002

Barton, E. L. (1993). Evidentials, argumentation, and epistemological stance. College English 55, 7, 745-769. https://doi.org/10.2307/378428

Bazerman, C. (1988). Shaping written knowledge, the genre and activity of the experimental article in science. Wisconsin: University of Wisconsin Press.

Biber, D., \& Finegan, E. (1988). Adverbial stance types in English. Discourse Processes 11, 1-34. https://doi.org/10.1080/01638538809544689

Biber, D., \& Finegan, E. (1989). Styles of stance in English: lexical and grammatical marking of evidentiality and affect. Text, 9(1), 93-124. https://doi.org/10.1515/text.1.1989.9.1.93

Conrad, S., \& Biber, D. (2000). Adverbial marking of stance in speech and writing. In S. Hunston, \& G. Thompson (Eds.), Evaluation in text: authorial stance and the construction of discourse (pp. 56-73). Oxford: Oxford University Press.

Çakır, H. (2016). Native and Non-Native Writers' Use of stance adverbs in English research article abstracts. Open Journal of Modern Linguistics, 6, 85-96. https://doi.org/10.4236/ojml.2016.62008 
Chafe, W. L. (1986). Evidentiality in English conversation and academic writing. In W. L. Chafe, \& J. Nichols (Eds.), Evidentiality: the linguistic coding of epistemology. Norwood, NJ: Ablex.

Charles, M. (2003). 'This mystery': a corpus-based study of the use of nouns to construct stance in theses from two contrasting disciplines. Journal of English for Academic Purposes, 2, 313-326. https://doi.org/10.1016/S1475-1585 (03)00048-1

Flowerdew, J. (2003). Signaling nouns in discourse. English for Specific Purposes, 22, 329-346. https://doi.org/10.1016/S0889-4906 (02)00017-0

Flowerdew, J. (2006). Use of signaling nouns in a learner corpus. International Journal of Corpus Linguistics, 11, 345-362. https://doi.org/10.1075/ijcl.11.3.07flo

Francis, G. (1986). Anaphoric nouns. Birmingham: English Language Research, University of Birmingham.

Francis, G. (1994). Labelling discourse: an aspect of nominal-group lexical cohesion. In M. Coulthard (Ed.), Advances in written text analysis (pp. 83-101). London: Routledge.

Fraser, B. (1980). Conversational mitigation. Journal of Pragmatics 4, 341-350. https://doi.org/10.1016/0378-2166 (80)90029-6

Halliday, M. A. K., \& Hasan, R. (1976). Cohesion in English. London: Longman.

Hinkel, E. (2001). Matters of cohesion in L2 academic texts. Applied Language Learning, 12, 111-132.

Holmes, J. (1984). Modifying illocutionary force. Journal of Pragmatics, 8, 345-365. https://doi.org/10.1016/0378-2166 (84)90028-6

Hoey, M. (2000). Persuasive rhetoric in linguistics: a stylistic study of some features of the language of Naom Chomsky. In S. Hunston, \& G. Thompson (Eds.), Evaluation in text: authorial stance and the construction of discourse (pp. 28-37). Oxford: OUP.

Hoye, L. (1997). Adverbs and modality in English. London: Longman.

Hunston, S. (1989). Evaluation in experimental research articles. Unpublished $\mathrm{PhD}$ thesis, University of Birmingham.

Hunston, S. (1993). Evaluation and ideology in scientific writing. In M. Ghadessy (Ed.), Register analysis: theory and practice (pp. 57-73). London: Pinter.

Hunston, S. (1994). Evaluation and organization in a sample of written academic discourse. In M. Coulthard (Ed.) Advances in written text analysis (pp. 191-218). London: Routledge.

Hunston, S., \& Francis, G. (2000). Pattern grammar. Amsterdam: John Benjamins. https://doi.org/10.1075/scl.4

Hyland, K. (2011). Disciplines and discourses: Social interactions in the construction of knowledge. In Starke-Meyerring, D., Paré, A. Artemeva, N., Horne, M., and Yousoubova, L. Writing in knowledge societies, (pp. 193-213).The WAC Clearinghouse, Fort Collins, Colorado.

Hyland, K. (1996). Writing without conviction: Hedging in science research articles. Applied Linguistics 17, 433-454. https://doi.org/10.1093/applin/17.4.433

Hyland, K. (1998). Boosting, hedging and the negotiation of academic knowledge. Text, 18(3), 349-382. https://doi.org/10.1515/text.1.1998.18.3.349

Hyland, K. (1999). Disciplinary discourses: writer stance in research articles. In C. N. Candlin, \& K. Hyland (Eds.), Writing: texts, processes and practices (pp. 99-121). London: Longman.

Hyland, K. (2000). Disciplinary discourses. London: Longman.

Hyland, K. (2002). Authority and invisibility: Authorial identity in academic writing. Journal of Pragmatics, 34, 1091-1112. https://doi.org/10.1016/S0378-2166 (02)00035-8

Hyland, K. (2004). Perspectives on genre. In K. Hyland (Ed.), Genre and second language writing (pp. 24-50). Ann Arbor, MI: The University of Michigan Press.

Hyland, K. (2005). Stance and engagement: a model of interaction in academic discourse. Discourse studies, 7(2), 173-192. https://doi.org/10.1177/1461445605050365

Hyland, K., \& Tse, P. (2005). Hooking the reader: A corpus study of evaluative that in abstracts. English for Specific Purposes 24, 123-139. https://doi.org/10.1016/j.esp.2004.02.002 
Ivanic, R. (1991). Nouns in search of a context. International Review of Applied Linguistics, 29(2), 93-114. https://doi.org/10.1515/iral.1991.29.2.93

Kafes, H. (2009). Authorial stance in academic English: Native and non-native academic speaker writers' use of stance devices (modal verbs) in research articles. Unpublished PhD Dissertation, Anadolu University, Turkey.

Martin, J. R., \& White, P. R. R. (2005). The language of evaluation: Appraisal in English. New York: Palgrave Macmillan. https://doi.org/10.1057/9780230511910

Moreno, A. I. (2004). Retrospective labelling in premise-conclusion metatext: An English and Spanish contrastive study of research articles on business and economics. Journal of English for Academic Purposes, 3, 321-339. https://doi.org/10.1016/j.jeap.2004.07.005

Mur Duenas, M. Pillar. (2003-2004). Analyzing stance in American and Spanish business management RAS: The case of sentence-initial "Retrospective labels". Journal of English studies, 4, 137-154.

Schmid, H. (2000). English abstract nouns as conceptual shells: From corpus to cognition. Berlin: Mouton de Gruyter. https://doi.org/10.1515/9783110808704

Scott, M. (1996). WordSmithTools. Oxford: Oxford University Press.

Silver, M. (2003).The stance of stance: a critical look at ways stance is expressed and modeled in academic discourse. Journal of English for Academic Purposes, 2, 359-374. https://doi.org/10.1016/S1475-1585 (03)00051-1

Sinclair, J. M. (1981). Planes of discourse. In S. N. A. Rizvi (Ed.). The two-fold voice: essays in honor of Ramesh Mohan (pp. 70-91). Salzburg: University of Salzburg.

Sinclair, J. M. (1992). Priorities in discourse analysis. In M. Coulthard (Ed.), Advances in spoken discourse analysis (pp. 79-88). London: Routledge.

Sinclair, J. M. (1993). Written discourse structure. In J. M. Sinclair, M. Hoey, \& G. Fox (Eds.), Techniques of description: Spoken and written discourse (pp. 6-31). London: Routledge.

Stotesbury, H. (2003). Evaluation in research article abstracts in the narrative and hard sciences. Journal of English for Academic Purpose, 2, 327-341. https://doi.org/10.1016/S1475-1585 (03)00049-3

Stubbs, M. (1996). Text and corpus analysis: computer-assisted studies of language and culture. Oxford: Blackwell.

Swales, J. (1990). Genre analysis: English for academic and research settings. Cambridge: Cambridge University Press.

Tadros, A. (1994). Predictive categories in expository text. In: M. Coulthard (Ed.), Advances in written text analysis (pp. 69-82). New York: Routledge.

Thetela, P. (1997). Evaluated entities and parameters of value in academic research articles. English for Specific Purposes, 16(2), 101-118. https://doi.org/10.1016/S0889-4906 (96)00022-1

Thompson, G., \& Ye, Y. (1991). Evaluation in the reporting verbs used in academic papers. Applied Linguistics, 12(4), 365-382. https://doi.org/10.1093/applin/12.4.365

Winter, E. O. (1982). Towards a contextual grammar of English. London: George Allen \& Unwin.

Uysal, H. H. (2014). A Cross-cultural study of indirectness and hedging in the conference proposals of English NS and NNS scholars. In A. Łyda, \& K. Warchał (Eds.), Occupying Niches: Interculturality, Cross-Culturality and Aculturality in Academic Research (pp. 179-195). Switzerland: Springer International Publishing.

Yağız, O., \& Demir, C. (2014). Hedging strategies in academic discourse: a comparative analysis of Turkish writers and native writers of English. Procedia-Social and Behavioral Sciences, 158, 260-268. https://doi.org/10.1016/j.sbspro.2014.12.085

Yağız, O., \& Demir, C. (2015). A comparative study of boosting in academic texts: A contrastive rhetoric. International Journal of English Linguistics, 5, 12-28. https://doi.org/10.5539/ijel.v5n4p12 


\section{Copyrights}

Copyright for this article is retained by the author(s), with first publication rights granted to the journal.

This is an open-access article distributed under the terms and conditions of the Creative Commons Attribution license (http://creativecommons.org/licenses/by/4.0/). 